\title{
Dietary Fatty Acids Regulate Hepatic Low Density Lipoprotein (LDL) Transport by Altering LDL Receptor Protein and mRNA Levels
}

\author{
Jay D. Horton, Jennifer A. Cuthbert, and David K. Spady \\ Department of Internal Medicine, The University of Texas Southwestern Medical Center at Dallas, Dallas, Texas 75235
}

\begin{abstract}
The concentration of LDL in plasma is strongly influenced by the amount and the type of lipid in the diet. Recent studies in the hamster have shown that dietary fatty acids differentially affect circulating LDL levels primarily by altering receptor-dependent LDL uptake in the liver. To investigate the mechanistic basis of this effect, rates of receptor-dependent LDL transport in the liver were correlated with LDL receptor protein and mRNA levels in hamsters fed safflower oil or coconut oil and varying amounts of cholesterol. Hepatic LDL receptor activity was significantly lower in animals fed coconut oil than in animals fed safflower oil at all levels of cholesterol intake $(26,53$, and $61 \%$ lower at cholesterol intakes of $0,0.06$, and $0.12 \%$, respectively). These fatty acid-induced changes in hepatic LDL receptor activity were accompanied by parallel changes in hepatic LDL receptor protein and $m$ RNA levels, suggesting that dietary fatty acids regulate the LDL receptor pathway largely at the mRNA level. (J. Clin. Invest. 1993.92:743-749.) Key words: dietary fatty acids - LDL transport • liver • LDL receptor mRNA
\end{abstract}

\section{Introduction}

A number of risk factors are known to contribute to the genesis of atherosclerosis and coronary heart disease. Of these, an elevated concentration of LDL in the plasma appears to be one of the most important (1). The concentration of LDL in plasma is determined by the rate at which LDL enters the plasma relative to the rate at which it is cleared from plasma by the various tissues of the body. LDL are formed in plasma during the metabolism of VLDL, which in turn are secreted by the liver (2). Tissues take up LDL from plasma by at least two mechanisms. One of these, termed receptor-dependent transport, involves the interaction of LDL particles with cell surface receptors, followed by endocytosis and catabolism of the LDL particle in the lysosomal compartment $(3,4)$. Tissues also take up LDL by a nonsaturable, receptor-independent process that is thought to represent bulk fluid phase endocytosis (5). In normal animals and humans, receptor-dependent mechanisms account for $70-80 \%$ of total LDL turnover (6-9) and the vast majority of receptor-dependent LDL uptake occurs in the liver (10-12). Thus, changes in the concentration of LDL in plasma

Address correspondence to Dr. David K. Spady, Department of Internal Medicine, University of Texas Southwestern Medical Center, 5323 Harry Hines Blvd., Dallas, TX 75235-8887.

Received for publication 3 December 1992 and in revised form 26 February 1993.

J. Clin. Invest.

(C) The American Society for Clinical Investigation, Inc.

0021-9738/93/08/0743/07 \$2.00

Volume 92, August 1993, 743-749 are generally due to changes in the rate of LDL production, changes in receptor-dependent LDL uptake by the liver, or changes in both of these processes.

The concentration of total and LDL cholesterol in plasma is strongly influenced by the amount and type of lipid in the diet (13-16). Thus, dietary triglycerides containing predominantly saturated fatty acids raise plasma LDL concentrations when compared with dietary triglycerides containing predominantly unsaturated fatty acids. Dietary cholesterol also raises plasma LDL concentrations, although individual responses vary widely (17). We have previously shown in the hamster that dietary lipids alter plasma LDL concentrations primarily by altering the rate of receptor-dependent LDL uptake by the liver $(18,19)$. When added to a low fat diet, cholesterol modestly suppresses receptor-dependent LDL uptake by the liver and raises circulating LDL levels. Dietary triglycerides containing predominantly saturated fatty acids greatly augment the suppressive effect of dietary cholesterol on receptor-dependent LDL uptake by the liver, whereas unsaturated fatty acids partially restore receptor activity. Thus, at any level of dietary cholesterol, receptor-dependent LDL uptake by the liver is always higher in animals fed unsaturated fatty acids than in animals fed saturated fatty acids.

The major form of regulation of the LDL receptor pathway demonstrated to date is sterol-mediated feedback repression of LDL receptor gene transcription (20-22). Dietary cholesterol presumably suppresses hepatic LDL receptor activity via this mechanism (23) and, indeed, dietary cholesterol has been shown to reduce hepatic LDL receptor mRNA levels in nonhuman primates (24). How dietary fatty acids regulate receptordependent LDL uptake by the liver has not been established. In these studies we examined this question by quantifying hepatic LDL receptor protein and mRNA levels and rates of receptordependent LDL transport in hamsters fed triglycerides containing predominantly saturated or unsaturated fatty acids. These studies demonstrate that regulation of hepatic LDL transport by dietary fatty acids is due largely, if not entirely, to changes in LDL receptor protein and mRNA levels.

\section{Methods}

Animals and diets. Male Golden Syrian hamsters (Sasco, Inc., Omaha, $\mathrm{NE}$ ) were housed in colony cages and subjected to light cycling for at least $3 \mathrm{wk}$ before introduction of the experimental diets. The control semisynthetic diet used in these studies contained $20 \%$ soy protein, $0.3 \%$ DL-methionine, $10 \%$ cellulose, $8.5 \%$ salt $\mathrm{mix}, 1 \%$ vitamin mix, $0.2 \%$ choline bitartrate, $2 \%$ corn oil, and $58 \%$ corn starch. The experimental diets were prepared by replacing corn starch with the desired amount of triglyceride on a cal/cal basis, assuming $4 \mathrm{cal} / \mathrm{g}$ of corn starch and $9 \mathrm{cal} / \mathrm{g}$ of triglyceride. The triglycerides used in these studies were safflower oil and hydrogenated coconut oil. The fatty acid composition of the safflower oil, as determined by capillary gas-liquid chromatography, was $7 \%$ as $16: 0,2 \%$ as $18: 0,12 \%$ as $18: 1$, and $78 \%$ as $18: 2$. The hydrogenated coconut oil contained $9 \%$ as $8: 0,6 \%$ as $10: 0,51 \%$ as 
$12: 0,17 \%$ as $14: 0,8 \%$ as $16: 0$, and $8 \%$ as $18: 0$. The diets were fed ad lib and all studies were carried out during the mid-dark phase of the light cycle.

Determination of hepatic LDL uptake rates in vivo. Plasma was obtained from normocholesterolemic hamster and human donors. The LDL was isolated from plasma by preparative ultracentrifugation in the density range of $1.020-1.055 \mathrm{~g} / \mathrm{ml}$ and labeled with ${ }^{125} \mathrm{I}$ - or ${ }^{131} \mathrm{I}$-tyramine cellobiose as previously described (25). The human LDL was also reductively methylated to completely eliminate its recognition by the LDL receptor (26). Rates of hepatic LDL uptake were measured using a primed infusion of ${ }^{125} \mathrm{I}$-tyramine cellobiose-labeled LDL. The infusions of ${ }^{125}$ I-tyramine cellobiose-labeled LDL were continued for 4 $\mathrm{h}$, at which time each animal was administered a bolus of ${ }^{131} \mathrm{I}$-tyramine cellobiose-labeled LDL as a volume marker and killed 10 min later by exsanguination through the abdominal aorta. Samples of the liver along with aliquots of plasma were assayed for radioactivity in a gamma counter (Packard Instruments, Meriden, CT). The amount of labeled LDL in the liver at $10 \mathrm{~min}\left({ }^{131} \mathrm{I}\right.$ disintegrations per minute per gram of liver divided by the specific activity of ${ }^{131} \mathrm{I}$ in plasma) and at $4 \mathrm{~h}$ ( ${ }^{125}$ I disintegrations per minute per gram of liver divided by the specific activity of ${ }^{125} \mathrm{I}$ in plasma) was then calculated. The increase in the tissue content of LDL cholesterol or LDL protein with time represents the rate of LDL uptake in micrograms of LDL cholesterol or LDL protein taken up per hour per gram of tissue.

Since receptor-dependent LDL uptake by the liver is saturable and since plasma LDL concentrations varied widely among the different experimental groups, changes in receptor-dependent LDL uptake could not be directly equated with changes in LDL receptor activity (27). To relate changes in receptor-dependent LDL uptake to changes in LDL receptor activity, the experimentally determined uptake rates were superimposed on kinetic curves describing the relationship between hepatic LDL uptake and circulating LDL concentrations in normal animals. By relating the rates of receptor-dependent and receptorindependent LDL uptake in the experimental animals to these normal kinetic curves, it was possible to determine how the various dietary manipulations affected LDL receptor activity (defined as the rate of receptor-dependent LDL uptake in an experimental animal relative to the rate of receptor-dependent LDL uptake seen in control animals at the same plasma LDL concentration).

Determination of LDL receptor protein levels. Liver membrane proteins were solubilized essentially as described by Schneider et al. (28) and solubilized LDL receptor protein determined by immunoblotting. Samples of hamster liver were homogenized in 5 vol of homogenization buffer ( $50 \mathrm{mM}$ Tris/maleate, $\mathrm{pH} 6.5,150 \mathrm{mM} \mathrm{NaCl}, 2 \mathrm{mM}$ $\mathrm{CaCl}_{2}, 1 \mathrm{mM}$ PMSF, and $2 \mu \mathrm{M}$ leupeptin) using a Dounce homogenizer ( 10 strokes with the loose and 5 with the tight pestle). The homogenate was centrifuged at $1,000 \mathrm{~g}$ for $10 \mathrm{~min}$ and the supernatant was centrifuged at $8,000 \mathrm{~g}$ for $20 \mathrm{~min}$. The $8,000-\mathrm{g}$ supernatent was centrifuged at $104,000 \mathrm{~g}$ for $60 \mathrm{~min}$. The pellet was suspended in a buffer containing $250 \mathrm{mM}$ Tris/maleate, $\mathrm{pH} 6.5,2 \mathrm{mM} \mathrm{CaCl}_{2}, 1 \mathrm{mM}$ PMSF, and $2.5 \mu \mathrm{M}$ leupeptin. An equal volume of a buffer containing $2 \%$ Triton $\mathrm{X}-100,320 \mathrm{mM} \mathrm{NaCl}$, and $2 \mathrm{mM} \mathrm{CaCl}_{2}$ was then added. The suspension was stirred at $4^{\circ} \mathrm{C}$ for $15 \mathrm{~min}$ and then centrifuged at $104,000 \mathrm{~g}$ for $1 \mathrm{~h}$. Aliquots of the supernatent containing $500 \mu \mathrm{g}$ protein were adjusted to $2 \%$ SDS and $0.2 \mathrm{M}$ sucrose and loaded onto a 7.5\% polyacrylamide gel. After electrophoresis (29), proteins were transferred to polyvinyldifluoride (PVDF) membrane (Immobilon-P; Millipore Corp., Bedford, MA) with $50 \mathrm{~V}$ for $14 \mathrm{~h}$ in buffer containing $25 \mathrm{mM}$ Tris, $\mathrm{pH} 8.3,192 \mathrm{mM}$ glycine, $0.01 \%$ SDS, and $20 \%$ ( vol/ vol) methanol. After electrophoretic transfer, membranes were blocked with 5\% nonfat dried milk and incubated with a 1:200 dilution of LDL receptor antiserum. Polyclonal, monospecific antiserum was prepared in New Zealand White rabbits against a synthetic peptide corresponding to the $\mathrm{COOH}$-terminal 13 amino acids of the hamster LDL receptor (30). After incubation with the primary antibody, the PVDF membrane was incubated with $0.5 \mu \mathrm{Ci} / \mathrm{ml}^{125} \mathrm{I}$-labeled donkey anti-rabbit antibody (Amersham Corp., Arlington Heights, IL). The radiolabeled bands were identified by autoradiography, excised, and assayed for radioactivity in a gamma counter. Identically sized pieces of membrane from above and below the radiolabeled bands were also counted as a measure of nonspecific background radioactivity.

Determination of $L D L$ receptor $m R N A$ levels. Hepatic LDL receptor and glyceraldehyde-3-phosphate dehydrogenase (GAPDH, ${ }^{1}$ used as an invariant control) mRNA levels were determined by nuclease protection as previously described $(31,32)$. cDNA probes were not available for Syrian hamster LDL receptor or GAPDH. Therefore, after reverse transcriptase synthesis of the complementary DNA, the PCR was used to amplify sequences encoding fragments of the LDL receptor and GAPDH cDNAs from Syrian hamster liver RNA. Oligonucleotide primers used to amplify the LDL receptor (5'-AAAGGATCCGTAGACTGGATCCATGGCAACATCTACTGGAC-3' and 5'AAAGAATTCATAGATGGCCAAGGAGAAGGGGTG-3') and GAPDH (5'-AAAGGATCCACTGGCGTCTTCACCACCATGGAG-3' and 5'-AAAGAATTCGTCATGGATGACCTTGGCCAGGGG-3') sequences were selected from areas of $100 \%$ homology in the published rat (33) and Chinese hamster (30) sequences (LDL receptor) or rat (34), human (34), and European hamster (35) sequences (GAPDH). The PCR was carried out sequentially for $5 \mathrm{~min}$ at $55^{\circ} \mathrm{C}, 2 \mathrm{~min}$ at $72^{\circ} \mathrm{C}$, and $45 \mathrm{~s}$ at $95^{\circ} \mathrm{C}$ for 30 cycles in a programmable thermal controller (MJ Research, Inc., Watertown, MA). The oligonucleotide primers were synthesized with restriction sites (BamHI and EcoRI) to allow direct subcloning of the amplified DNA into the plasmid pGEM (Promega Corp., Madison, WI) for sequencing and into the bacteriophage M13 (Pharmacia LKB Biotechnology Inc., Piscataway, $\mathrm{NJ}$ ) for the preparation of ${ }^{32} \mathrm{P}$-labeled single-stranded probes. Probes were synthesized as previously described (32) using $0.5 \mu \mathrm{M}$ $\left[{ }^{32} \mathrm{P}\right] \mathrm{dCTP}$ and $1 \mu \mathrm{M}$ (LDL receptor) or $300 \mu \mathrm{M}$ (GAPDH) unlabeled dCTP. The sizes of the full-length, undigested, single-stranded cDNA probes, including M13 sequences, were 500 nucleotides for the LDL receptor and 240 nucleotides for GAPDH.

Samples of hamster liver were homogenized in guanidinium isothiocyanate and the RNA was isolated by centrifugation on cesium chloride. Total RNA $(40 \mu \mathrm{g})$ was hybridized with the ${ }^{32} \mathrm{P}$-labeled cDNA probes simultaneously at $48^{\circ} \mathrm{C}$ overnight. Unhybridized probe, present in excess relative to the amount of specific mRNA, was then digested with $40 \mathrm{U}$ of mung bean nuclease (GIBCO BRL, Gaithersburg, MD). The mRNA-protected ${ }^{32} \mathrm{P}$-labeled probes were separated on $7 \mathrm{M}$ urea, $6 \%$ polyacrylamide gels together with ${ }^{32} \mathrm{P}$-labeled MspI-digested pBR322 size standards and identified by autoradiography. The radiolabeled bands were excised and assayed for radioactivity by liquid scintillation spectroscopy. Identically sized bands from samples containing no RNA were also counted as a measure of nonspecific background radioactivity. The levels of GAPDH mRNA did not vary with dietary changes and were used to correct for any procedural losses.

Determination of liver and plasma cholesterol distribution. Hepatic esterified and unesterified cholesterol were separated using silicic acid/ celite columns and quantified by capillary gas-liquid chromatography (36). The cholesterol distribution in plasma was determined by gel filtration chromatography using a Superose 6 column (Sigma Chemical Co., St. Louis, MO). 2-ml aliquots were collected and assayed for cholesterol using an enzymatic kit (Boehringer Mannheim Corp., Indianapolis, IN).

\section{Results}

Dietary fatty acids affect plasma LDL concentrations primarily by altering receptor-dependent LDL uptake in the liver. These studies were undertaken to determine the extent to which changes in LDL receptor number and mRNA levels contribute to these fatty acid-induced changes in hepatic LDL transport. Groups of animals were fed diets containing predominantly

1. Abbreviations used in this paper: ACAT, acyl-CoA:cholesterol acyltransferase; GAPDH, glyceraldehyde-3-phosphate dehydrogenase; PVDF, polyvinyldifluoride; SRE 1, sterol regulatory element 1 . 
saturated (coconut oil) or unsaturated (safflower oil) fatty acids and varying amounts of cholesterol $(0,0.06$, or $0.12 \%)$ for $6 \mathrm{wk}$. At the end of the feeding period, rates of receptor-dependent LDL uptake by the liver were correlated with LDL receptor protein and mRNA levels. Fig. 1 shows the effect of the experimental diets on plasma LDL cholesterol concentrations. On the cholesterol-free diet, plasma LDL cholesterol concentrations were significantly higher in animals fed the saturated triglyceride than in animals fed the unsaturated triglyceride ( $55 \mathrm{vs} 31 \mathrm{mg} / \mathrm{dl}, P<0.01$ ). The differential effect of saturated and unsaturated lipids was greater when modest amounts of cholesterol were added to the diet. In animals fed $0.06 \%$ cholesterol ( $\sim 120 \mathrm{mg} / \mathrm{kcal})$, mean plasma LDL-cholesterol concentrations equaled 148 and $65 \mathrm{mg} / \mathrm{dl}(P<0.01)$ on the saturated and unsaturated triglyceride diets, respectively. In animals fed $0.12 \%$ cholesterol $(\sim 240 \mathrm{mg} / \mathrm{kcal})$, the corresponding values were 262 and $104 \mathrm{mg} / \mathrm{dl}(P<0.01)$.

Absolute rates of total and receptor-independent LDL uptake by the liver were measured in vivo using homologous and methylated human LDL, respectively. Receptor-dependent LDL uptake was taken as the difference between total and receptor-independent uptake. Since receptor-dependent LDL uptake is saturable, and since mean plasma LDL concentrations varied by nearly 10 -fold among the different experimental groups, changes in absolute rates of LDL uptake by the liver could not be equated directly with changes in receptor activity. To calculate changes in hepatic LDL receptor activity, it was necessary to relate the changes in absolute rates of LDL uptake in the experimental animals to kinetic curves describing the relationship between LDL uptake and circulating LDL concentrations in control animals.

Fig. 2 shows the kinetic curves for normal hepatic LDL transport in control hamsters. The shaded areas represent the relationship between total (stippled) and receptor-independent (hatched) LDL uptake and plasma LDL concentrations over the range of $\mathrm{LDL}$ concentrations observed in these studies. These kinetic curves were previously established by quantifying rates of total and receptor-independent LDL uptake in control animals under conditions where plasma LDL concentrations were acutely raised and maintained at various levels by infusions of unlabeled LDL (27). Superimposed on these standard kinetic curves are the mean rates of total and receptor-independent LDL uptake determined in these studies. Values for animals fed safflower oil are shown in the top panel of Fig. 2 and values for animals fed coconut oil are shown in the bottom panel.

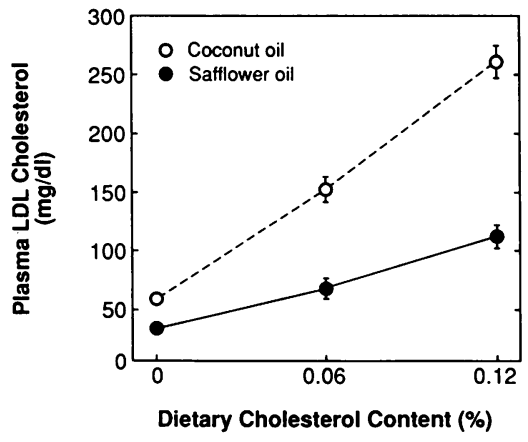

Figure 1. Plasma LDL cholesterol concentrations in animals fed saturated and unsaturated fatty acids. Animals were fed a semisynthetic diet supplemented with $20 \%$ (by weight) safflower oil or coconut oil and varying amounts of cholesterol for $6 \mathrm{wk}$. Each value represents the mean \pm SE for data

obtained in 10-12 animals. Differences between the safflower and coconut oil groups were significant $(P<0.01)$ at each level of dietary cholesterol.
Figure 2. Determination of hepatic receptordependent LDL transport. The shaded areas represent the kinetic curves for total (stippled) and receptor-independent ( hatched) LDL cholesterol uptake determined in control animals as described in Methods. Superimposed on these standard kinetic curves are the absolute rates of total and receptor-independent LDL cholesterol uptake in animals fed the safflower oil (top) or coconut oil (bottom) diets plotted as a function of the plasma LDL cholesterol concentration in the same animals. Each point represents the mean for data obtained in 10-12 animals.

In control animals, rates of total (solid triangles) and receptor-independent (open triangles) LDL cholesterol uptake equaled 36 and $3 \mu \mathrm{g} / \mathrm{h}$ per $\mathrm{g}$, respectively, at a plasma LDL cholesterol concentration of $31 \mathrm{mg} / \mathrm{dl}$. These values fell on the standard kinetic curves for LDL transport, and hepatic LDL receptor activity in these animals was assigned a value of $100 \%$. Hepatic LDL receptor activity in each of the experimental groups was then calculated by dividing the rate of receptor-dependent LDL uptake in the experimental animals by the rate of receptor-dependent LDL uptake that would be seen in normal animals at the same plasma LDL cholesterol concentration. For example, as illustrated in the bottom panel of Fig. 2, rates of total (solid circle) and receptor-independent (open circle) LDL cholesterol uptake in animals fed coconut oil equaled 53 and $4 \mu \mathrm{g} / \mathrm{h}$ per $\mathrm{g}$, respectively, at a plasma LDL cholesterol concentration of $55 \mathrm{mg} / \mathrm{dl}$. These values were not displaced from the standard kinetic curves, indicating no change in the receptor-dependent or -independent pathways. In contrast, the rate of total LDL cholesterol uptake in animals fed coconut oil plus $0.12 \%$ cholesterol ( solid square) equaled $50 \mu \mathrm{g} / \mathrm{h}$ per g at a plasma LDL cholesterol concentration of $278 \mathrm{mg} / \mathrm{dl}$, whereas normal animals would transport $\sim 118 \mu \mathrm{g} / \mathrm{h}$ per $\mathrm{g}$ at this LDL concentration. Since receptor-independent LDL transport was normal in these animals $(21 \mu \mathrm{g} / \mathrm{h}$ per $\mathrm{g})$, the reduction in total LDL cholesterol uptake could be attributed entirely to a reduction in receptor-dependent transport. Thus, the rate of receptor-dependent LDL uptake in animals fed coconut oil and $0.12 \%$ cholesterol $(50-21=29 \mu \mathrm{g} / \mathrm{h}$ per $\mathrm{g})$ was suppressed by $70 \%$ relative to the rate that would be seen in control animals at the same plasma LDL concentration $(118-21=97 \mu \mathrm{g} / \mathrm{h}$ per $\mathrm{g}$ ).

From the type of analysis illustrated in Fig. 2, hepatic LDL receptor activity (defined as the rate of receptor-dependent LDL uptake in experimental animals relative to the rate of receptor-dependent LDL uptake in control animals at the same plasma LDL cholesterol concentration) was calculated for 


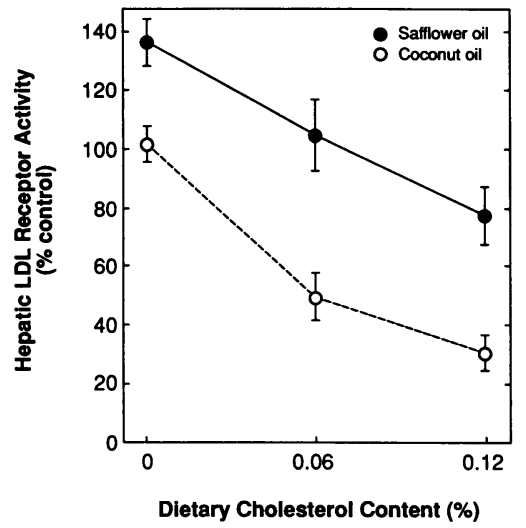

each of the experimental groups and these values are shown in Fig. 3. When added to a cholesterol-free diet, safflower oil increased hepatic LDL receptor activity by $\sim 35 \%$, whereas coconut oil had no effect. Dietary cholesterol suppressed hepatic LDL receptor activity in both groups; however, the effect of cholesterol was much greater in animals fed coconut oil than in animals fed safflower oil. On the $0.06 \%$ cholesterol diet, hepatic LDL receptor activity equaled 49 and $103 \%$ of the control value in animals fed coconut oil and safflower oil, respectively. On the $0.12 \%$ cholesterol diet, hepatic LDL receptor activity equaled 30 and $77 \%$ of the control value in animals fed coconut oil and safflower oil, respectively. Thus, hepatic LDL receptor activity was significantly lower $(P<0.01)$ in animals fed coconut oil than in animals fed safflower oil at all levels of cholesterol intake $(26,53$, and $61 \%$ lower at cholesterol intakes of 0 , 0.06 , and $0.12 \%$, respectively).

In parallel studies, identically treated groups of animals were used to prepare hepatic membranes for the determination of LDL receptor protein and to obtain liver samples for the isolation of total RNA. A representative autoradiogram depicting changes in LDL receptor protein in animals fed saturated and unsaturated triglycerides is shown in Fig. 4, and the mean changes in LDL receptor protein are summarized in Fig. 5. On a cholesterol-free diet, LDL receptor protein in solubilized liver membranes was $16 \%$ higher in animals fed safflower oil than in animals fed coconut oil $(P>0.05)$. As with rates of receptordependent LDL transport, dietary cholesterol suppressed hepatic LDL receptor protein in both groups; however, the effect of cholesterol was much greater in animals fed the coconut oil than in animals fed the safflower oil. When the diet contained $0.06 \%$ cholesterol, hepatic LDL receptor protein equaled 52 and $93 \%$ of the control value in animals fed coconut oil and safflower oil, respectively. On the $0.12 \%$ cholesterol diet, hepatic LDL receptor protein equaled 36 and $80 \%$ of the control value in animals fed coconut oil and safflower oil, respectively. Thus, relative to the unsaturated triglyceride, the saturated triglyceride reduced hepatic LDL receptor protein by 44 ( $P$ $<0.01)$ and $55 \%(P<0.01)$ in animals fed 0.06 and $0.12 \%$ cholesterol, respectively.

LDL receptor mRNA levels were quantified by nuclease protection using single-stranded cDNA probes specific for the Golden Syrian hamster. A representative autoradiogram depicting the changes in hepatic LDL receptor mRNA levels in animals fed saturated and unsaturated triglycerides is shown in Fig. 6, and the mean changes in LDL receptor mRNA levels are

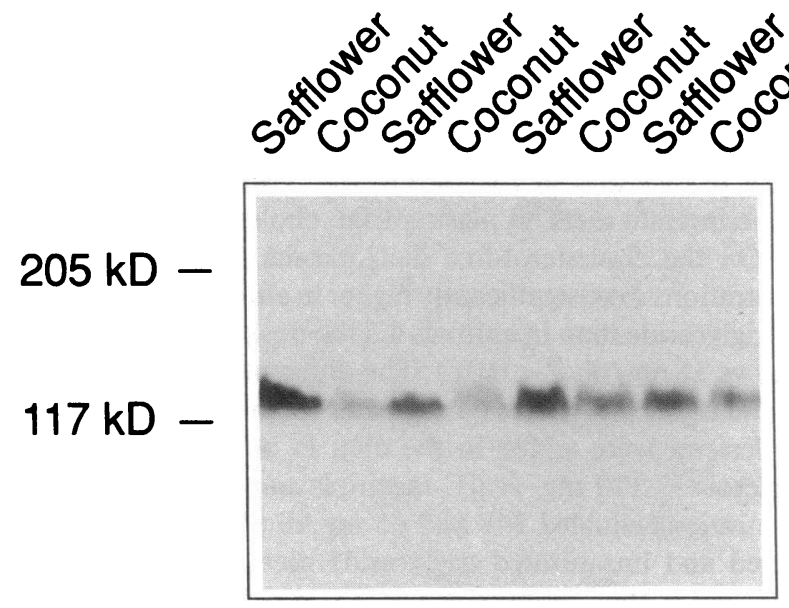

Figure 4. Immunoblotting of LDL receptor from solubilized liver membranes. Hepatic membranes were prepared from animals fed a semisynthetic diet supplemented with $20 \%$ (by weight) safflower oil or coconut oil and $0.06 \%$ cholesterol for $6 \mathrm{wk}$. Solubilized liver membrane proteins ( $500 \mu \mathrm{g} /$ lane) were separated on $7.5 \%$ polyacrylamide gels. The proteins were transferred electrophoretically to PVDF membrane and incubated with a 1:200 dilution of antiserum raised against a synthetic peptide corresponding to the $\mathrm{COOH}$-terminal 13 amino acids of the hamster LDL receptor. After incubation with the primary antibody, the PVDF paper was incubated with 0.5 $\mu \mathrm{Ci} / \mathrm{ml}^{125} \mathrm{I}$-labeled donkey anti-rabbit antibody and the dried membranes were subjected to autoradiography.

summarized in Fig. 7. On a cholesterol-free diet, hepatic LDL receptor activity was $27 \%$ higher in animals fed safflower oil than in animals fed coconut oil $(P<0.025)$. Dietary cholesterol suppressed hepatic LDL receptor mRNA levels in both groups, but again the effect of cholesterol was much greater in animals fed the coconut oil than in animals fed the safflower oil. When the diet contained $0.06 \%$ cholesterol, hepatic LDL receptor mRNA equaled 58 and $102 \%$ of the control value in animals fed coconut oil and safflower oil, respectively. On the $0.12 \%$ cholesterol diet, hepatic LDL receptor mRNA equaled 38 and $85 \%$ of the control value in animals fed coconut oil and safflower oil, respectively. Thus, relative to the unsaturated triglyceride, the saturated triglyceride reduced hepatic LDL receptor mRNA by $43(P<0.01)$ and 55\% $(P<0.01)$ in animals fed 0.06 and $0.12 \%$ cholesterol, respectively. Overall, the changes in hepatic LDL receptor activity shown in Fig. 3 could be accounted for largely by changes in LDL receptor protein and mRNA, suggesting that dietary fatty acids may regulate the LDL receptor pathway at the transcriptional level. As shown in Fig. 8, there was a significant correlation between the changes

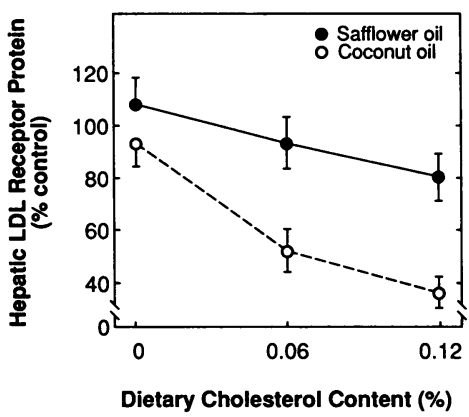

Figure 5. Regulation of hepatic LDL receptor protein levels by dietary saturated and unsaturated fatty acids. Each point represents the mean \pm 1 SE for data obtained from 9-12 animals. Differences between the safflower and coconut oil groups were significant ( $P$ $<0.01)$ in animals fed 0.06 and $0.12 \%$ cholesterol. 


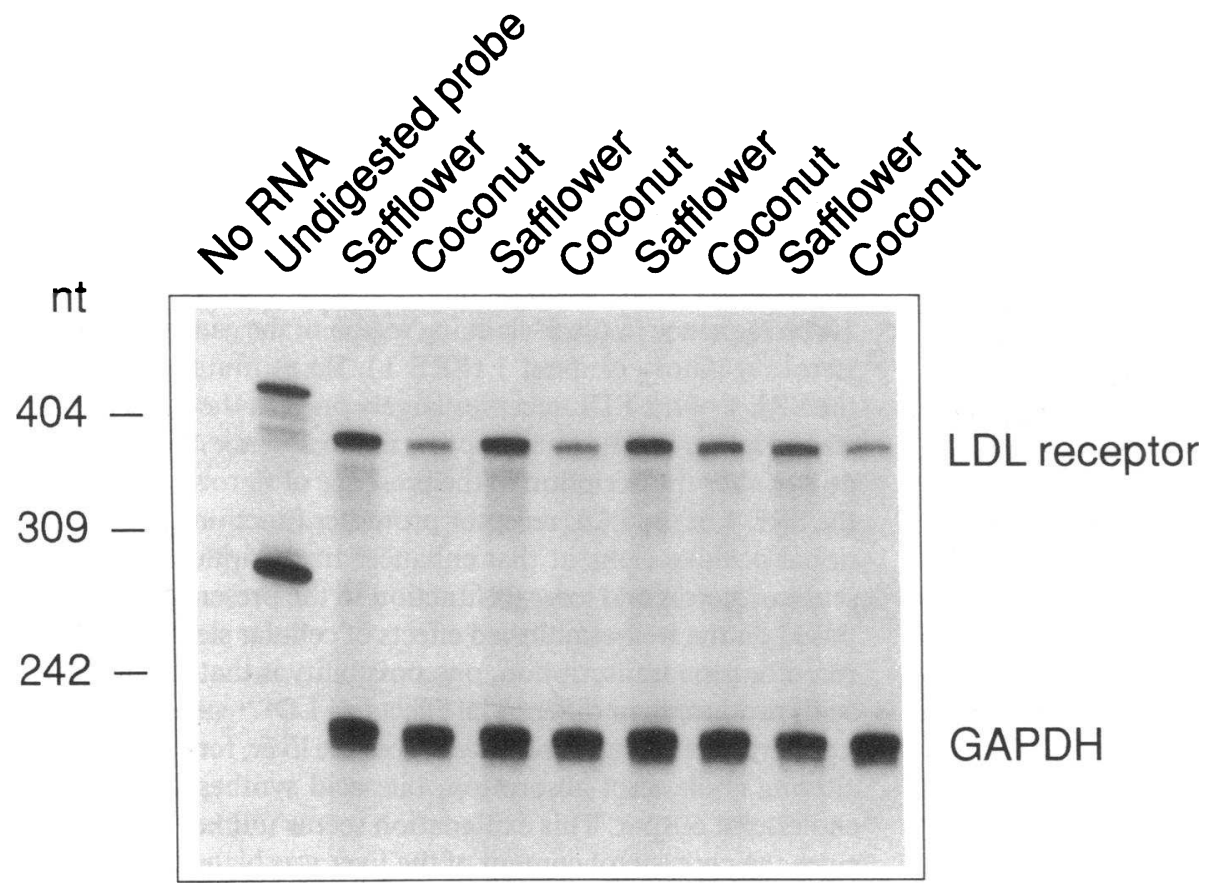

Figure 6. Measurement of hepatic LDL receptor mRNA levels. Hepatic RNA was isolated from animals fed a semisynthetic diet supplemented with $20 \%$ (by weight) safflower oil or coconut oil and $0.06 \%$ cholesterol for $6 \mathrm{wk}$. Total RNA $(40 \mu \mathrm{g})$ was hybridized with ${ }^{32} \mathrm{P}$ labeled probes and the LDL receptor and GAPDH bands resistant to mung bean nuclease digestion were analyzed by polyacrylamide gel electrophoresis followed by autoradiography as described in Methods.

in LDL receptor protein and the changes in LDL receptor mRNA levels when both parameters were measured in the same liver $(r=0.67)$.

The major form of regulation of the LDL receptor pathway demonstrated to date is feedback repression of receptor gene transcription by cellular sterols. One possibility is that dietary fatty acids regulate LDL receptor mRNA levels by altering the content or distribution of sterols in the liver. Fig. 9 shows the changes in hepatic esterified and unesterified cholesterol levels in animals fed the various experimental diets. On a cholesterolfree diet, the cholesteryl ester content of the liver was significantly higher in animals fed safflower oil than in animals fed coconut oil ( 0.8 vs $0.4 \mathrm{mg} / \mathrm{g}, P<0.01)$. Dietary cholesterol increased hepatic cholesteryl esters in both groups; however, the increase was much greater in animals fed safflower oil than in animals fed coconut oil. These data indicate that fatty acids do not regulate the LDL receptor pathway simply by altering the cholesterol content of the liver, since unsaturated fatty acids increased LDL receptor mRNA levels under circumstances where the total and esterified cholesterol content of the liver was also increased. As shown in the bottom panel, the two dietary triglycerides did not differentially affect the total unesterified cholesterol content of the liver.

\section{Discussion}

The concentration of LDL in plasma is strongly influenced by the amount and type of triglyceride in the diet. Dietary triglycerides containing predominantly saturated fatty acids increase total and LDL cholesterol concentrations relative to the same amount of an unsaturated triglyceride in both animals and humans. The effects of dietary triglycerides on the major transport processes that control circulating LDL levels have been examined in detail in the hamster $(18,19)$. These studies have shown that dietary fatty acids produce their differential effects on circulating LDL levels primarily by altering receptor-dependent LDL uptake in the liver. Thus, relative to triglycerides containing predominantly saturated fatty acids, triglycerides containing predominantly unsaturated fatty acids accelerate the rate of receptor-dependent LDL uptake in the liver, thereby lowering plasma LDL concentrations. The present studies show that these fatty acid-induced changes in receptor-depen-

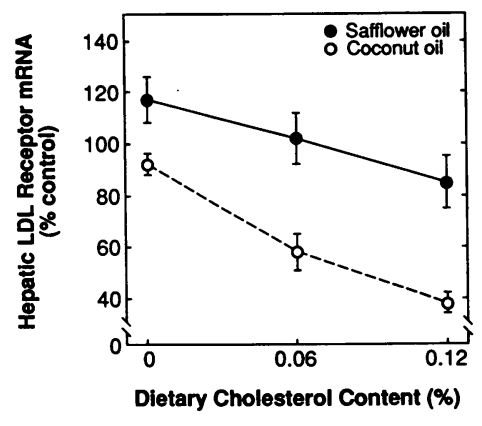

Figure 7. Regulation of hepatic LDL receptor mRNA levels by dietary saturated and unsaturated fatty acids. Each point represents the mean \pm 1 SE for data obtained in 9-12 animals. Differences between the safflower and coconut oil groups were significant in animals fed the cholesterolfree $\operatorname{diet}(P<0.025)$ and in animals fed the 0.06 and $0.12 \%$ cholesterol diets $(P$ $<0.01$ ).

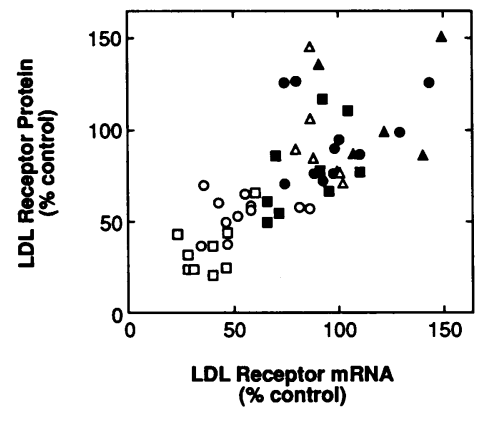

Figure 8. Correlation between hepatic LDL receptor protein and mRNA levels. The change in LDL receptor protein is plotted as a function of the change in LDL receptor mRNA for animals where both parameters were determined in the same liver $(r=0.67)$. The open and closed symbols represent animals fed coconut and safflower oil,

respectively, with either 0 (triangles), 0.06 (circles), or $0.12 \%$ (squares) cholesterol. 


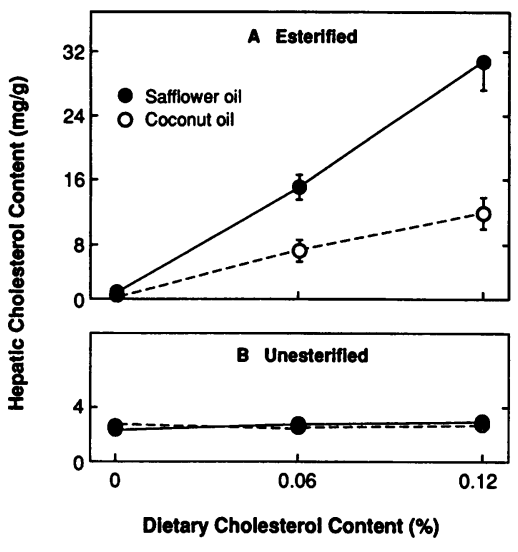

Figure 9. Regulation of hepatic cholesterol levels by dietary saturated and unsaturated fatty acids. Each point represents the mean $\pm 1 \mathrm{SE}$ for data obtained in 10 12 animals. Differences between the safflower and coconut oil groups were significant $(P$ $<0.01$ ) at each level of dietary cholesterol.

dent LDL transport in the liver are accompanied by parallel changes in $\mathrm{LDL}$ receptor protein and $\mathrm{mRNA}$ levels. These data suggest that dietary fatty acids regulate the LDL receptor pathway largely at the mRNA level.

The diets used in these studies were rich in triglycerides containing almost exclusively saturated or unsaturated fatty acids. These diets were specifically chosen to maximize the differential effects of dietary fatty acids on hepatic LDL transport and thereby provide the best opportunity for examining the mechanism of this effect. In addition, varying amounts of cholesterol were added to the diet since an interaction between dietary cholesterol and fatty acids exists whereby small amounts of cholesterol magnify the differential effects of saturated and unsaturated fatty acids (19). The two triglycerides used in these studies produced significant differences in receptor-dependent LDL transport at all levels of cholesterol intake and these differences in receptor activity could be accounted for largely by changes in LDL receptor protein and mRNA levels. Whether a similar mechanism accounts for the smaller changes in hepatic LDL receptor activity seen with less drastic alterations in dietary fatty acids is not known. About one-third to one-half of the fatty acids present in typical Western diets are saturated. If half of these saturated fatty acids were replaced by unsaturated fatty acids or carbohydrate, hepatic LDL receptor activity would increase by $25-30 \%$ and plasma LDL concentrations would fall by $20-25 \%$ (37), changes that if sustained could reduce the risk of mortality from coronary heart disease by as much as $50 \%$ in humans (38). Unfortunately, the changes in hepatic LDL receptor activity that occur under these clinically relevant conditions are quite small and it may not be possible to reliably investigate the underlying mechanisms using currently available techniques.

Previous studies investigating the effect of dietary triglycerides on hepatic LDL receptor mRNA levels have yielded mixed results. Two groups have shown that saturated and unsaturated triglycerides produce no differential effects on hepatic LDL receptor mRNA levels in monkeys whether added to low or high cholesterol diets $(24,39)$. A third group reported a significant differential effect of saturated and unsaturated triglycerides on hepatic LDL receptor mRNA levels in one subgroup of baboons; however, in this study the dietary triglycerides produced no differential effects on plasma $\beta$-lipoprotein or apo B concentrations (40). Of note, in none of these studies were receptor mRNA levels correlated with actual rates of receptordependent LDL uptake in the liver. Thus, it is possible that the fatty acid-induced changes in receptor-dependent transport were smaller than anticipated, making changes in LDL receptor mRNA levels difficult to detect.

The mechanism whereby dietary fatty acids differentially regulate LDL receptor mRNA levels is not known. The principal mechanism of regulation of the LDL receptor pathway demonstrated to date is feedback repression of LDL receptor gene transcription by cellular sterols $(20,21)$. Sterol-mediated regulation of the LDL receptor promoter has been localized to a 10-bp sequence in the 5 -flanking region of the gene termed the sterol regulatory element 1 (SRE 1). Point mutations within the SRE 1 of the LDL receptor largely prevent the induction of transcription that normally occurs in the absence of sterols, but do not alter transcription in the presence of sterols (22). Thus, the SRE 1 of the LDL receptor promoter functions as a conditional positive element that enhances transcription in the absence of sterols and loses its function in the presence of sterols. Based on the well-established effects of cellular sterols on LDL receptor gene transcription, one possibility is that dietary fatty acids produce their differential effects on LDL receptor mRNA levels by altering sterol balance across the liver, for example, by altering cholesterol absorption, bile acid synthesis, or biliary cholesterol output. This explanation seems unlikely, however, since the cholesterol content of the liver was higher in animals fed unsaturated fatty acids than in animals fed saturated fatty acids.

Alternatively, dietary fatty acids may alter the distribution of cholesterol within the hepatocyte. The fraction of total cellular cholesterol that is metabolically active and involved in sterol-mediated regulation of LDL receptor gene expression is likely to be very small. This small regulatory pool of unesterified cholesterol is in equilibrium with a much larger pool of unesterified structural cholesterol located primarily in plasma membranes and with a storage pool of esterified cholesterol located in the cytoplasm. The activity of the cholesterol esterifying enzyme acyl-CoA:cholesterol acyltransferase (ACAT) is known to be higher in animals fed unsaturated fatty acids than in animals fed saturated fatty acids (41). Thus, saturated fatty acids may inhibit ACAT activity, resulting in an expansion of the putative regulatory pool of free cholesterol (or related derivative) that mediates feedback repression of the LDL receptor pathway. Conversely, unsaturated fatty acids may accelerate cholesterol esterification leading to depletion of this regulatory pool of cholesterol. That changes in ACAT activity may lead to regulation of the LDL receptor pathway has been demonstrated in studies with ACAT inhibitors. Thus, preincubation of cultured HepG2 cells (42), cultured rat hepatocytes (43), or cultured J774 macrophages (44) with specific inhibitors of ACAT markedly enhances the sensitivity of the LDL receptor pathway to downregulation by lipoprotein cholesterol.

Finally, free fatty acids (45) and fatty acyl CoAs (46) have been shown to differentially regulate the expression of several genes, including genes encoding transcription factors. Thus, it is possible that dietary fatty acids may regulate $\mathrm{LDL}$ receptor mRNA levels through a mechanism that does not involve classic sterol-mediated regulation of gene transcription (47).

\section{Acknowledgments}

The authors wish to thank Chris White and Jody Houston for excellent technical assistance.

This research was supported by National Institutes of Health grant HL-38409 and a grant-in-aid from the American Heart Association. 
While these studies were carried out, Dr. Horton was also supported by U.S. Public Health Service training grant AM-07100.

\section{References}

1. Consensus Conference. 1985. Lowering blood cholesterol to prevent hear disease. JAMA (J. Am. Med. Assoc.) . 253:2080-2086.

2. Havel, R. J. 1984. The formation of LDL: mechanisms and regulation. $J$. Lipid Res. 25:1570-1576.

3. Goldstein, J. L., R. G. W. Anderson, and M. S. Brown. 1979. Coated pits, coated vesicles, and receptor-mediated endocytosis. Nature (Lond.). 279:679685.

4. Brown, M. S., and J. L. Goldstein. 1986. A receptor-mediated pathway for cholesterol homeostasis. Science (Wash. DC). 232:34-47.

5. Scharschmidt, B. F., J. R. Lake, E. L. Renner, V. Licko, and R. W. Van Dyke. 1986. Fluid phase endocytosis by cultured rat hepatocytes and perfused rat liver: implications for plasma membrane turnover and vesicular trafficking of fluid phase markers. Proc. Natl. Acad. Sci. USA. 83:9488-9492.

6. Bilheimer, D. W., Y. Watanabe, and T. Kita. 1982. Impaired receptor-mediated catabolism of low density lipoprotein in the WHHL rabbit, an animal model of familial hypercholesterolemia. Proc. Natl. Acad. Sci. USA. 79:33053309.

7. Pittman, R. C., T. E. Carew, A. D. Attie, J. L. Witztum, Y. Watanabe, and D. Steinberg. 1982. Receptor-dependent and receptor-independent degradation of low density lipoprotein in normal and in receptor-deficient mutant rabbits. $J$. Biol. Chem. 257:7994-8000.

8. Steinbrecher, U. P., J. L. Witztum, Y. A. Kesaniemi, and R. L. Elam. 1983 Comparison of glucosylated low density lipoprotein with methylated or cyclohexanedione-treated low density lipoprotein in the measurement of receptor-independent low density lipoprotein catabolism. J. Clin. Invest. 71:960-964.

9. Spady, D. K., S. D. Turley, and J. M. Dietschy. 1985. Receptor-independent low density lipoprotein transport in the rat in vivo. Quantitation, characterization, and metabolic consequences. J. Clin. Invest. 76:1113-1122.

10. Spady, D. K., D. W. Bilheimer, and J. M. Dietschy. 1983. Rates of receptor-dependent and -independent low density lipoprotein uptake in the hamster. Proc. Natl. Acad. Sci. USA. 80:3499-3503.

11. Spady, D. K., M. Huettinger, D. W. Bilheimer, and J. M. Dietschy. 1987. Role of receptor-independent low density lipoprotein transport in the maintenance of tissue cholesterol balance in the normal and WHHL rabbit. J. Lipid Res. 28:32-41.

12. Bilheimer, D. W., J. L. Goldstein, S. M. Grundy, T. E. Starzl, and M. S. Brown. 1984. Liver transplantation to provide low-density-lipoprotein receptors and lower plasma cholesterol in a child with homozygous familial hypercholesterolemia. N. Engl. J. Med. 311:1658-1664.

13. Keys, A., J. T. Anderson, and F. Grande. 1965. Serum cholesterol response to changes in the diet. I. Iodine value of dietary fat versus 2S-P. Metab. Clin. Exp. 14:747-758.

14. Hegsted, D. M., R. B. McGandy, M. L. Meyers, and F. J. Stare. 1965 Quantitative effects of dietary fat on serum cholesterol in man. Am. J. Clin. Nutr. 17:281-295.

15. Keys, A., J. T. Anderson, and F. Grande. 1965. Serum cholesterol response to changes in the diet. II. The effect of cholesterol in the diet. Metab. Clin. Exp. 14:759-765.

16. Connor, W. E., D. B. Stone, and R. E. Hodges. 1964. The interrelated effects of dietary cholesterol and fat upon human serum lipid levels. J. Clin. Invest. 43:1691-1696.

17. Beynen, A. C., M. B. Katan, and L. F. M. Van Zutphen. 1987. Hypo- and hyperresponders: individual differences in the response of serum cholesterol concentration to changes in diet. Adv. Lipid Res. 22:115-171.

18. Spady, D. K., and J. M. Dietschy. 1985. Dietary saturated triacylglycerols suppress hepatic low density lipoprotein receptors in the hamster. Proc. Natl. Acad. Sci. USA. 82:4526-4530.

19. Spady, D. K., and J. M. Dietschy. 1988. Interaction of dietary cholesterol and triglycerides in the regulation of hepatic low density lipoprotein transport in the hamster. J. Clin. Invest. 81:300-309.

20. Sudhof, T. C., D. W. Russell, M. S. Brown, and J. L. Goldstein. 1987. 42 bp element from LDL receptor gene confers end-product repression by sterols when inserted into viral TK promoter. Cell. 48:1061-1069.

21. Dawson, P. A., S. L. Hofmann, D. R. van der Westhuyzen, T. C. Südhof M. S. Brown, and J. L. Goldstein. 1988. Sterol-dependent repression of low density lipoprotein receptor promoter mediated by 16-base pair sequence adjacent to binding site for transcription factor Spl. J. Biol. Chem. 263:3372-3379.

22. Smith, J. R., T. F. Osborne, J. L. Goldstein, and M. S. Brown. 1990. Identification of nucleotides responsible for enhancer activity of sterol regulatory element in low density lipoprotein receptor gene. J. Biol. Chem. 265:2306-2310.

23. Ma, P. T. S., G. Gil, T. Südhof, D. W. Bilheimer, J. L. Goldstein, and M. S. Brown. 1986. Mevinolin, an inhibitor of cholesterol synthesis, induces mRNA for low density lipoprotein receptor in livers of hamsters and rabbits. Proc. Natl. Acad. Sci. USA. 83:8370-8374.

24. Sorci-Thomas, M., M. D. Wilson, F. L. Johnson, D. L. Williams, and L. L. Rudel. 1989. Studies on the expression of genes encoding apolipoproteins B100 and B48 and the low density lipoprotein receptor in nonhuman primates: comparison of dietary fat and cholesterol. J. Biol. Chem. 264:9039-9045.

25. Glass, C. K., R. C. Pittman, G. A. Keller, and D. Steinberg. 1983. Tissue sites of degradation of apoprotein A-I in the rat. J. Biol. Chem. 258:7161-7167.

26. Mahley, R. W., K. H. Weisgraber, G. W. Melchior, T. L. Innerarity, and K. S. Holcombe. 1980. Inhibition of receptor-mediated clearance of lysine and arginine-modified lipoproteins from the plasma of rats and monkeys. Proc. Natl. Acad. Sci. USA. 77:225-229.

27. Spady, D. K., J. B. Meddings, and J. M. Dietschy. 1986. Kinetic constants for receptor-dependent and receptor-independent low density lipoprotein transport in the tissues of the rat and hamster. J. Clin. Invest. 77:1474-1481.

28. Schneider, W. J., U. Beisiegel, J. L. Goldstein, and M. S. Brown. 1982. Purification of the low density lipoprotein receptor, an acidic glycoprotein of 164,000 molecular weight. J. Biol. Chem. 257:2664-2673.

29. Laemmli, U. K. 1970. Cleavage of structural proteins during the assembly of the head of bacteriophage T4. Nature (Lond.). 227:680-685.

30. Bishop, R. W. 1992. Structure of the hamster low density lipoprotein receptor gene. J. Lipid Res. 33:549-557.

31. Williams, D. L., T. C. Newman, G. S. Shelness, and D. A. Gordon. 1986 Measurement of Apolipoprotein mRNA by DNA-excess solution hybridization with single-stranded probes. Methods Enzymol. 128:671-689.

32. Spady, D. K., and J. A. Cuthbert. 1992. Regulation of hepatic sterol metabolism in the rat. J. Biol. Chem. 267:5584-5591.

33. Lee, L. Y., W. A. Mohler, B. L. Schafer, J. S. Freudenberger, N. ByrneConnolly, K. B. Eager, S. T. Mosley, J. K. Leighton, R. N. Thrift, R. A. Davis, and R. D. Tanaka. 1989. Nucleotide sequence of the rat low density lipoprotein receptor cDNA. Nucleic Acids Res. 17:1259-1260.

34. Tso, J. Y., X.-H. Sun, T.-h. Kao, K. S. Reece, and R. Wu. 1985. Isolation and characterization of rat and human glyceraldehyde-3-phosphate dehydrogenase cDNAs: genomic complexity and molecular evolution of the gene. Nucleic Acids Res. 13:2485-2501.

35. Vincent, S., and P. Fort. 1990. Nucleotide sequence of hamster glyceraldehyde-3-phosphate dehydrogenase mRNA. Nucleic Acids Res. 18:3054.

36. Andersen, J. M., and J. M. Dietschy. 1978. Relative importance of high and low density lipoproteins in the regulation of cholesterol synthesis in the adrenal gland, ovary, and testis of the rat. J. Biol. Chem. 253:9024-9032.

37. Woollett, L. A., D. K. Spady, and J. M. Dietschy. 1992. Saturated and unsaturated fatty acids independently regulate low density lipoprotein receptor activity and production rate. J. Lipid Res. 33:77-88.

38. Lipid Research Clinics Program. 1984. The Lipid Research Clinics Coronary Primary Prevention Trial results. II. The relationship of reduction in incidence of coronary heart disease to cholesterol lowering. JAMA (J. Am. Med. Assoc.). 251:365-374.

39. Hennessy, L. K., J. Osada, J. M. Ordovas, R. J. Nicolosi, A. F. Stucchi, M. E. Brousseau, and E. J. Schaefer. 1992. Effects of dietary fats and cholesterol on liver lipid content and hepatic apolipoprotein A-I, B, and E and LDL receptor mRNA levels in cebus monkeys. J. Lipid Res. 33:351-360.

40. Fox, J. C., H. C. McGill, Jr., K. D. Carey, and G. S. Getz. 1987. In vivo regulation of hepatic LDL receptor $\mathrm{mRNA}$ in the baboon: differential effects of saturated and unsaturated fat. J. Biol. Chem. 262:7014-7020.

41. Spector, A. A., T. L. Kaduce, and R. W. Dane. 1980. Effect of dietary fat saturation on acylcoenzyme A:cholesterol acyltransferase activity of rat liver microsomes. J. Lipid Res. 21:169-179.

42. Havekes, L. M., E. C. De Wit, and H. M. G. Princen. 1987. Cellular free cholesterol in Hep G2 cells is only partially available for down-regulation of low-density-lipoprotein receptor activity. Biochem. J. 247:739-746.

43. Salter, A. M., N. Ekins, M. Al-Seeni, D. N. Brindley, and B. Middleton. 1989. Cholesterol esterification plays a major role in determining low-density-lipoprotein receptor activity in primary monolayer cultures of rat hepatocytes. Biochem. J. 263:255-260.

44. Tabas, I., D. A. Weiland, and A. R. Tall. 1986. Inhibition of acyl coenzyme A:cholesterol acyl transferase in $\mathrm{J} 774$ macrophages enhances down-regulation of the low density lipoprotein receptor and 3-hydroxy-3-methylglutarylcoenzyme A reductase and prevents low density lipoprotein-induced cholesterol accumulation. J. Biol. Chem. 261:3147-3155.

45. Distel, R. J., G. S. Robinson, and B. M. Spiegelman. 1992. Fatty acid regulation of gene expression: transcriptional and post-transcriptional mechanisms. J. Biol. Chem. 267:5937-5941.

46. Henry, M. F., and J. E. Cronan, Jr. 1992. A new mechanism of transcriptional regulation: release of an activator triggered by small molecule binding. Cell. 70:671-679.

47. Ellsworth, J. L., C. Chandrasekaran, and A. D. Cooper. 1991. Evidence for sterol-independent regulation of low-density lipoprotein receptor activity in HepG2 cells. Biochem. J. 279:175-187. 